\title{
PARALLEL UNIT-CONNECTED GENERATOR MODEL FOR THIRD HARMONIC STATOR GROUND FAULT PROTECTION
}

\author{
G.A. Adepoju ${ }^{1}$, S.O.A. Ogunjuyigbe ${ }^{2}$, T.I. Brimmo ${ }^{3}$ \\ ${ }^{1}$ Department of Electronic and Electrical Engineering, Ladoke Akintola University of Technology, Ogbomoso, Oyo \\ State, Nigeria \\ ${ }^{2}$ Department of Electronics and Electrical Engineering, University of Ibadan, Ibadan, Oyo State, Nigeria \\ ${ }^{3}$ Electrical Department, Mainstream Energy Solutions Limited-Kainji Hydro Power Plant, Kainji, Niger state, Nigeria
}

\begin{abstract}
Conventional ground fault protection schemes can be applied for any generator terminal connection but it covers at most $95 \%$ of generator stator length. 100\% protection for synchronous generator stator winding can be achieved by a combination of zero sequence and third harmonic protection schemes. The implementation of the third harmonic scheme on any generator is determined by magnitude of third harmonic voltage produced in the generator. The methods of connecting the generator terminal also influence the range of third harmonic voltage at the stator terminal and neutral. An investigation into the compatibility of particular generator configuration with the third harmonic scheme is important to prevent protection mal-operation since the scheme is hampered in performance by certain factors which include grounding method employed and generator terminal connection among others. In this paper, the modelling of parallel unit-connected generators of the second order is presented to study the influence of parallel unit-connected generators on third harmonic stator ground fault protection. Application of mesh analysis method to the circuit models produced ordinary non-linear algebraic equations. The equations were solved using Cramer's rule. Simulations of the circuit models were performed for no-load, light load and full load conditions using MATLAB/SIMULINK to study the character of third harmonic voltage at stator neutral and terminal when a ground fault occurs to validate the results of the models. Introduction of a ground fault at the neutral point of the single generator showed that the third harmonic voltage decreased towards zero at the neutral but increased towards maximum at the terminal.
\end{abstract}

Keywords: Generator, MATLAB/SIMULINK, Harmonic

\section{INTRODUCTION}

Ground faults are a major cause of stator winding damage. A ground fault in the stator winding of a synchronous generator causes the flow of current whose magnitude is dependent on the grounding method employed on the generator and also limited by the fault impedance [1]. The flow of the fault current if not interrupted often results in insulation breakdown of the stator winding and burning of lamination portions in severe cases.

Ordinary zero sequence voltage relays used for winding protection against single phase ground faults on unit connected generators cannot cover $100 \%$ of stator winding, i.e. there is a dead zone at or near the generator neutral [2] Zero sequence voltage relays can only detect faults over 90$95 \%$ of the stator winding. Typically $5 \%-10 \%$ of the winding portion is unprotected. [3]. A combination of zero sequence voltage relays and relays tuned to the third harmonic voltage provide $100 \%$ protection for the generator stator winding [4].

Third harmonic voltage is produced by all generators and is present in the two ends of the stator winding in all generators but in different magnitude. The magnitude varies according to the machine design, the load level, the measurement point and the fault location along the winding.
Its normal values are between $1 \%$ and $6 \%$ of the nominal generator voltage, in the case of non-faulted windings [5].

A generator is suitable for third harmonic protection if enough third harmonic voltage is produced in it during normal operation. The third harmonic voltage can be used to excite third harmonic relays to determine the presence of a ground fault. The implementation of the third harmonic protection depends on where the third harmonic voltage is measured. It can be measured in the generator terminal, neutral or both.

When a ground fault occurs near the neutral end of the stator winding, the value of third harmonic voltage at that point of the stator decreases towards zero but towards the terminal point of the stator, it increases towards maximum. Alternately for a fault close to the generator terminal, the reverse is the case [5]

This character of third harmonic voltage at the neutral and terminal of a generator form the basis of the third harmonic protection. The three possible measurement positions form the basis of the under voltage, overvoltage and ratio approaches to implementing the protection [6] The distribution of third harmonic voltage along the stator winding terminal and neutral positions in normal and fault conditions is shown in Figures 1 and 2 [7]. 
Generator terminal connections are however a major influence on a stator ground fault protection scheme excited by the third harmonic voltage [8]. Investigation of the influence of particular generator terminal connection on the range and character of third harmonic voltage present in the stator ends to excite protective relays is therefore important to prevent mal-operation of the protection scheme.

Parallel unit-connected generator is one of such terminal connections that can influence the character of third harmonic voltage hence the performance of third harmonic protection schemes.

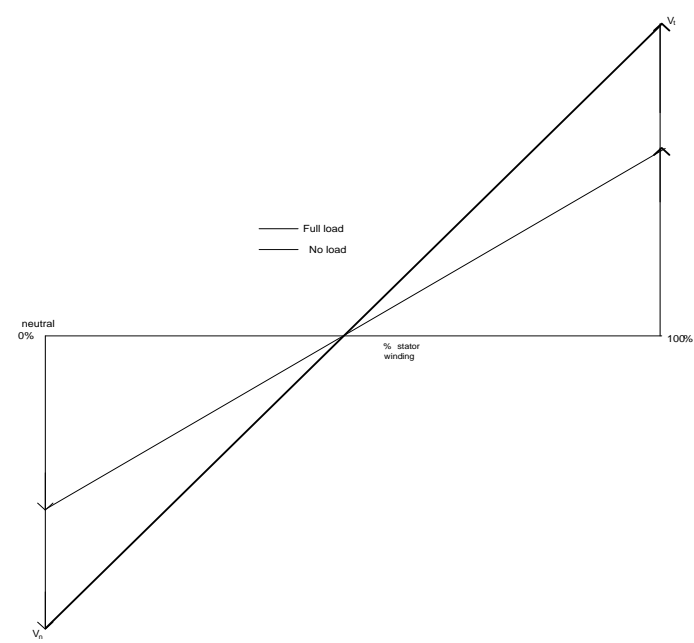

Fig 1: Normal third harmonic voltage distribution.

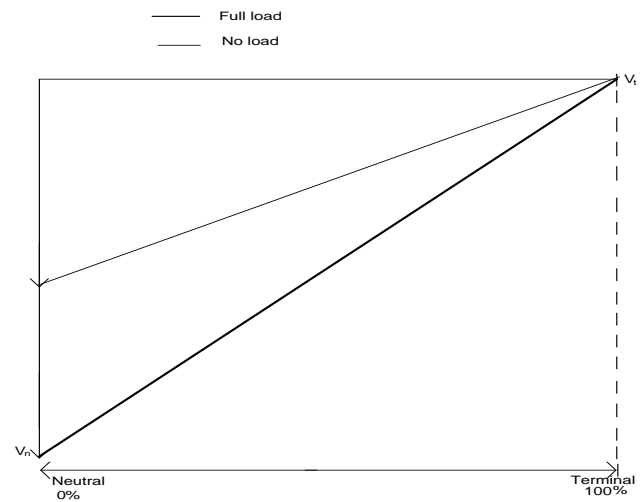

Fig 2a: Third harmonic voltage at terminal under fault.

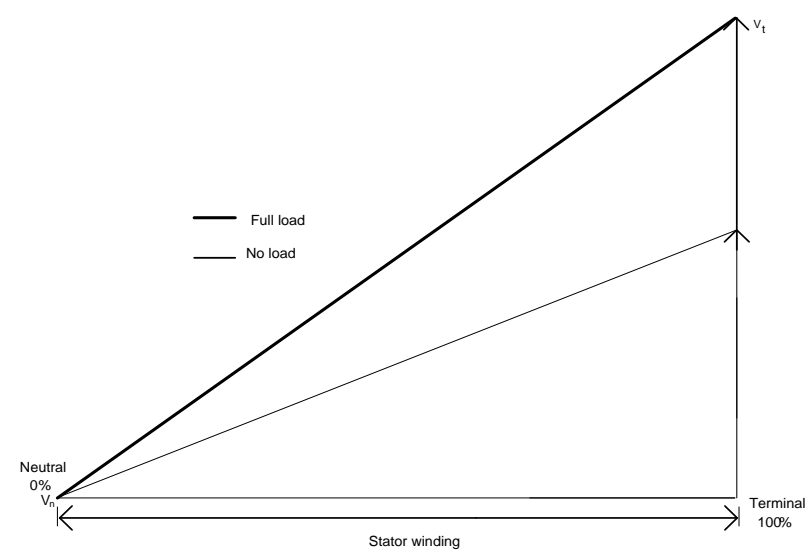

Fig 2b: Third harmonic voltage at neutral under fault.

\section{METHODOLOGY}

A typical parallel unit-connected generator of the second order is shown in Figure 3. In order to study the phenomenon of interest, the parallel unit-connected generator is modelled to represent a condition of normal operation and a condition when a ground fault has occurred along the stator winding.

The two conditions are referred to as non-fault and fault conditions of the unit. In modelling the unit, the stator winding capacitance to ground and the capacitances of the elements at the generator terminals are modelled as single capacitors to ground [5]. The third harmonic voltage feeding the measuring element of ground fault protection scheme is influenced by generator active power [9] therefore the study will be for no-load, light load and full load conditions of the unit.

Third harmonic voltage in the stator winding varies in magnitude according to the measurement point and the fault location along the winding [5] therefore different values of fault resistance in different portions of the winding were applied to the fault model.

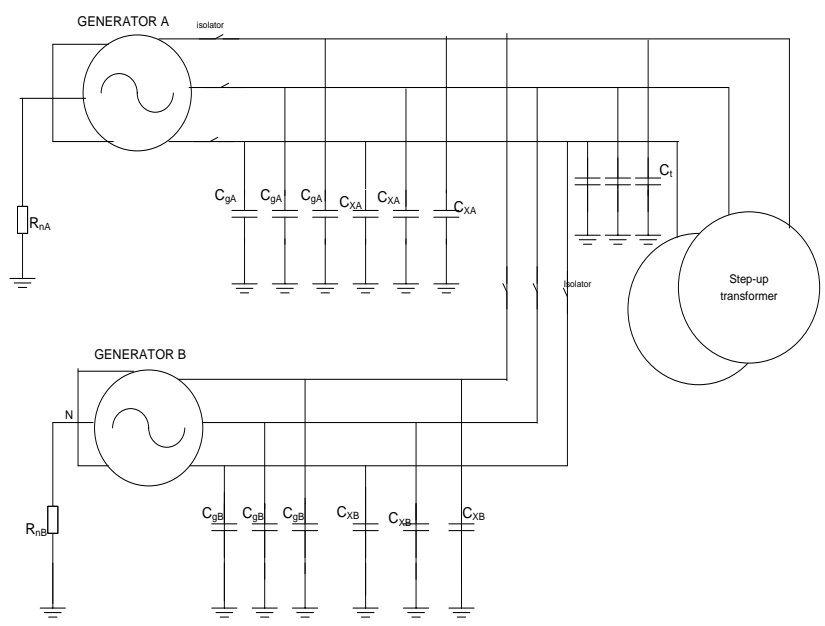

Fig 3: Typical two generators in-parallel

For the parallel unit-connected generator shown in Figure 3, $\mathrm{C}_{\mathrm{gA}}, \mathrm{C}_{\mathrm{gB}}=$ stator winding capacitance to ground of generators $\mathrm{A} \& \mathrm{~B}$

$\mathrm{C}_{\mathrm{xA}}, \mathrm{C}_{\mathrm{xB}}=$ Total capacitance to ground of all elements connected to generator terminals.

$R_{n A}, R_{n B}=$ Neutral resistance for generators A \& B.

$\mathrm{C}_{\mathrm{t}}=$ Step-up transformer capacitance to ground

The non-fault circuit model of the unit is presented in Figures 4 and 5. In order to study the ground fault phenomenon, a resistance was connected to ground on a phase of the generator as shown in Figure 6 . The voltage distribution across the terminal and neutral of the generators under normal operating condition is determined from the non-fault model.

The third harmonic voltage at the stator terminals vary in a normal operation from when a ground fault occurs in the 
stator winding of one of the generators. The change in voltage distribution under a fault condition was determined from the fault model.

For the non-fault and fault models of Figures $4-6$,

$E_{31}, E_{32}=$ Third harmonic voltage produced in generators 1 $\& 2$.

$C_{g}=$ Phase capacitance to ground of the stator winding.

$\mathrm{C}_{\mathrm{x} 1}, \mathrm{C}_{\mathrm{x} 2}=$ Total capacitance of elements connected to generators $1 \& 2$.

$\mathrm{R}_{\mathrm{n} 1}, \mathrm{R}_{\mathrm{n} 2}=$ Neutral resistance of generators $1 \& 2$.

$\mathrm{R}_{\mathrm{f}}=$ Fault resistance

$\alpha=$ Fault location along stator from neutral to terminal.

Performing parallel summation of $\mathrm{Cg} / 2, \mathrm{Cx}_{1}$ and $\mathrm{Cx}_{2}$ in Figure 4 yields the equivalent circuit of Figure 5.

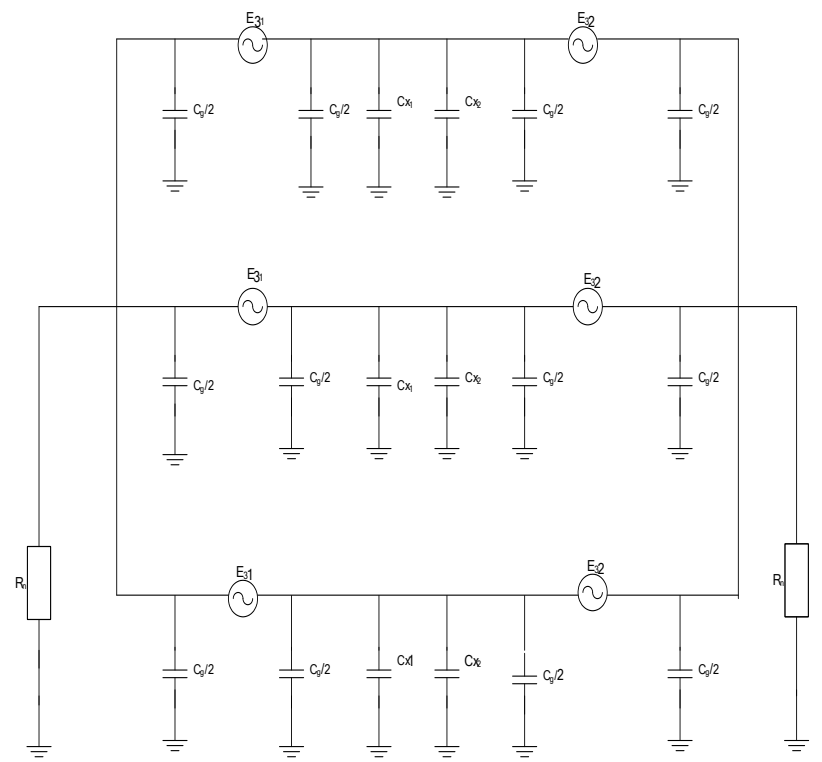

Fig 4: Non-fault model

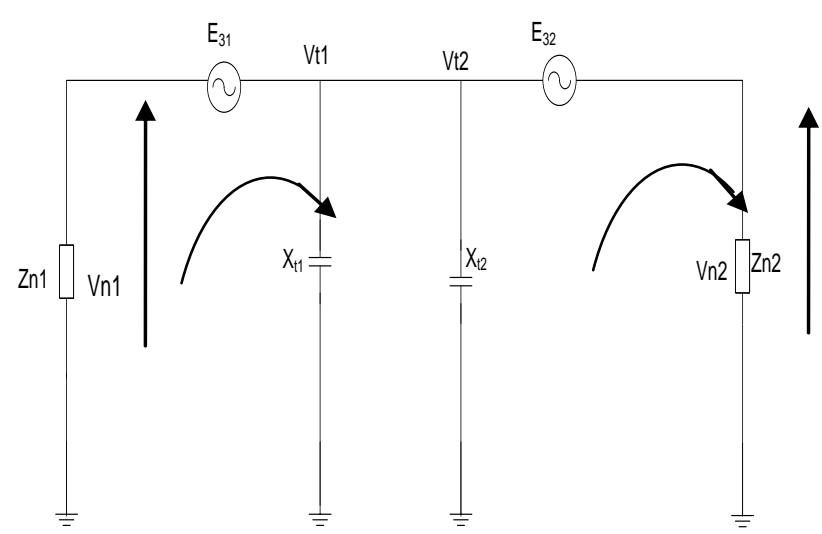

Fig 5: Simplified non-fault zero sequence voltage circuit

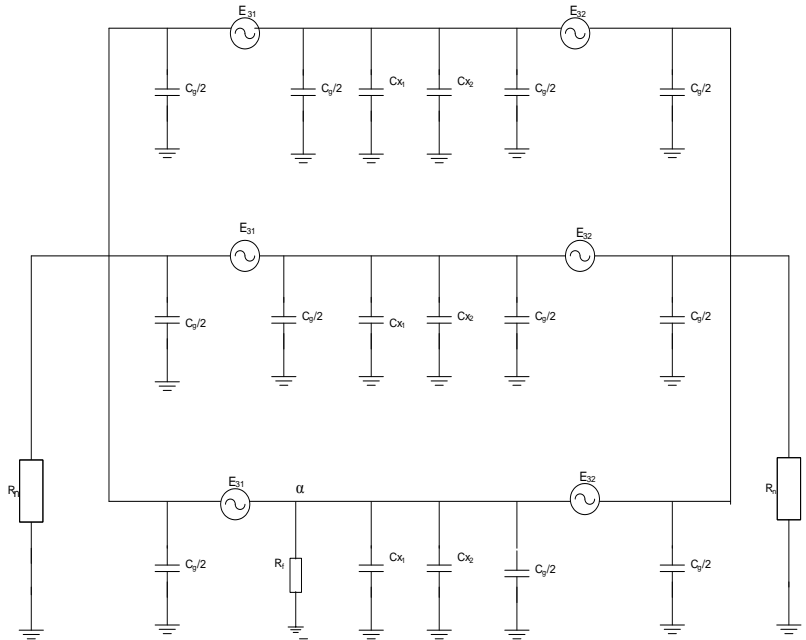

Fig 6: Two-generator fault model

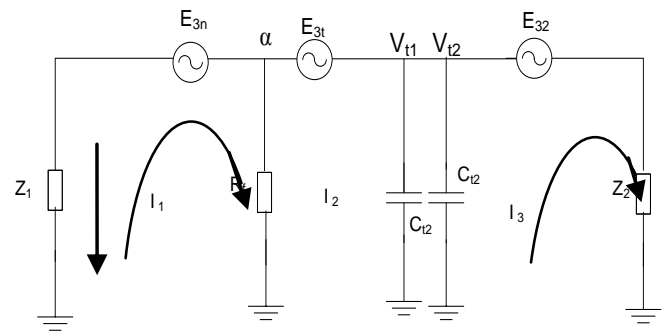

Fig 7: Simplified fault zero sequence voltage circuit

From Figures (5) and (6), the circuit analysis gives the following equations

$$
\begin{aligned}
& X_{t 1}=X_{t 2}=\frac{1}{\left(2 \pi f C_{t}\right)(1) C_{t}}=\left[\frac{1}{2} C_{g}+C_{X}\right] \\
& \left.Z_{n 1}=Z_{n 2}=\sqrt{\left[\left(X_{n}\right)^{2}+\left(3 R_{n}\right)^{2}\right.}\right]
\end{aligned}
$$

Where

$$
X_{n}=\frac{1}{2 \pi f C_{n}}
$$

Application of mesh analysis to the circuit of Figure 5 produces:

$$
\begin{aligned}
& E_{31}=I_{1}\left(Z_{1}+X_{t 1}\right)-I_{2} X_{t 2} \\
& E_{32}=I_{1} X_{t 2}-I_{2}\left(X_{t 2}-Z_{2}\right)
\end{aligned}
$$

In matrix form

$$
\left[\begin{array}{c}
E_{31} \\
E_{32}
\end{array}\right]=\left[\begin{array}{c}
I_{1} \\
I_{2}
\end{array}\right]\left[\begin{array}{cc}
Z_{1}+X_{t 1} & -X_{t 2} \\
X_{t 2} & X_{t 2}-Z_{2}
\end{array}\right]
$$


Or

$$
\mathrm{E}=\mathrm{IZ}
$$

Substituting for voltages, generator parameters and application of cramer's rule to equation 6 gives

$$
\left[\begin{array}{l}
92.5 \\
92.5
\end{array}\right]=\left[\begin{array}{l}
I_{1} \\
I_{2}
\end{array}\right]\left[\begin{array}{cc}
1718.4-j 2482.9 & j 1135.4 \\
-j 1135.4 & 1718.4-j 212.5
\end{array}\right]
$$

$$
E_{31}=E_{32}=92.5
$$

$$
\begin{aligned}
\Delta_{0}= & {[\{(1718.4-j 2482.9) \times(1718.4-j 212.5)\}] } \\
& -[\{(j 1135.4)(-j 1135.4)\}]
\end{aligned}
$$

$\Delta_{0}=664792646$

On light load condition, the terminal and neutral voltages are obtained from $9-12$.

$$
\Delta_{1}=\left[\begin{array}{cc}
92.5 & j 1135.4 \\
92.5 & 1718.4-j 212.5
\end{array}\right]
$$

$$
\Delta_{1}=202017.9
$$$$
I_{1}=0.0303 \mathrm{~A}
$$

$$
\Delta_{2}=\left[\begin{array}{cc}
1718.4-j 212.5 & 92.5 \\
j 1135.4 & 92.5
\end{array}\right]
$$

Note that $\Delta$ is the determinant of impedance matrix A. $\Delta_{1}$ and $\Delta_{2}$ are the determinant of matrix formed by replacing the $1^{\text {st }}$ and $2^{\text {nd }}$ column of $\mathrm{Z}$ by $\mathrm{E}$.

$$
\begin{aligned}
& \Delta_{2}=202017.9 \\
& I_{2}=0.0303 \mathrm{~A} \\
& V_{n 1}=V_{n 2}=I_{1} Z_{n 1} \\
& V_{n 1}=V_{n 2}=66.3 \mathrm{~V} \\
& V_{t 1}=V_{t 2}=I_{1} X_{t 1} \\
& V_{t 1}=V_{t 2}=34.5 \mathrm{~V}
\end{aligned}
$$

\section{ANALYSIS OF THE FAULT MODEL}

The value of voltage at terminal and neutral of both generators when a fault occurs on one of the pair can also be evaluated from the analysis of the fault model of Figure 7 as follows.

$$
E_{3 n}=I_{1}\left(R_{f}-Z_{n 1}\right)-I_{2} R_{f}
$$

$$
\begin{aligned}
& E_{3 t}=I_{1} R_{f}+I_{2}\left(X_{t 1}-R_{f}\right)+I_{3} X_{t 1} \\
& E_{32}=I_{2} X_{t 2}-I_{3}\left(X_{t 2}-Z_{n 2}\right)
\end{aligned}
$$

In matrix form

$$
\left[\begin{array}{c}
E_{3 n} \\
E_{3 t} \\
E_{32}
\end{array}\right]=\left[\begin{array}{c}
I_{1} \\
I_{2} \\
I_{3}
\end{array}\right]\left[\begin{array}{ccc}
R_{f}-Z_{n 1} & -R_{f} & 0 \\
R_{f} & X_{t 1}-R_{f} & X_{t 1} \\
0 & X_{t 2} & X_{t 2}-Z_{n 2}
\end{array}\right]
$$

Using cramer's rule on the matrix of equation 16 yields:

$$
\begin{aligned}
& I_{1}=\frac{\Delta_{1}}{\Delta_{0}} \\
& I_{2}=\frac{\Delta_{2}}{\Delta_{0}} \\
& I_{3}=\frac{\Delta_{3}}{\Delta_{0}} \\
& V_{n 1}=I_{1} Z_{n 1} \\
& V_{n 2}=I_{3} Z_{n 2} \\
& V_{t 1}=\left(I_{2}+I_{3}\right) X_{t 1} \\
& V_{t 2}=\left(I_{3}-I_{2}\right) X_{t 2}
\end{aligned}
$$

The voltage at terminal and neutral of the generators under different fault conditions can be calculated from equations $17-23$.

\subsection{Parallel Generator Simulink Non-Fault Model}

The non-fault model for a single generator is shown in Figure 8. The parallel generator SIMULINK model consists of a back to back connection of two of the single models of Figure 8. The generator parallel connection can be operated in a single generator mode or parallel operation mode.

When the generators are in parallel operation, capacitance at the terminal of each generator is modelled as a parallel summation of the capacitance at the terminals of individual generator. For a condition of operation of one generator with the other shutdown, the capacitance at the terminal of the generator in operation is modelled as a parallel summation of the capacitance at the terminal of the running generator and the capacitance at the terminal of the shutdown generator up to the open circuit breaker. 


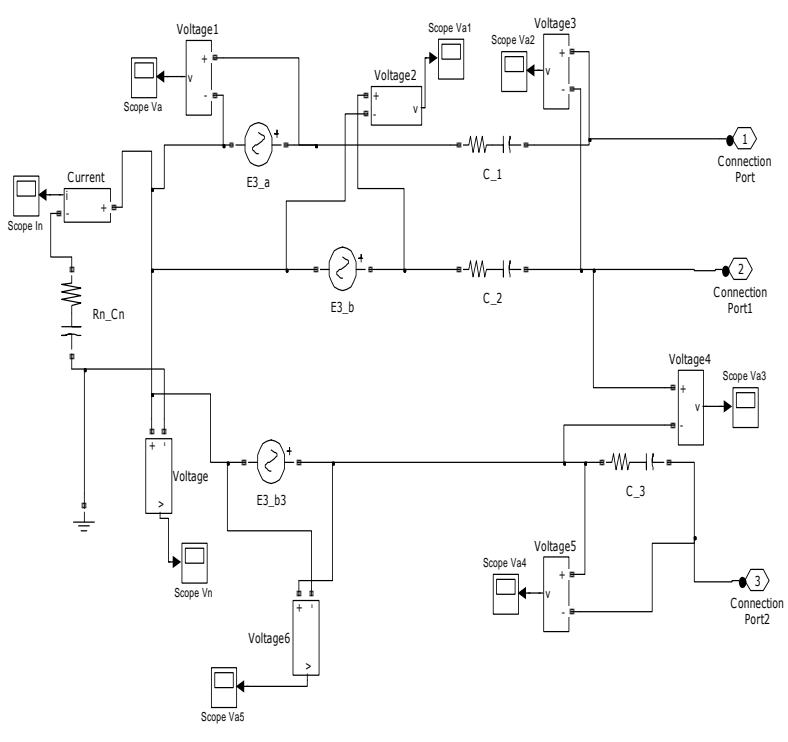

Fig 8: Single generator SIMULINK model

\section{RESULTS AND DISCUSSION}

\subsection{Validation of the Non-Fault Model}

In order to verify that the circuit models presented to sudy the phenomenon of interest are built correctly using SIMULINK, validation of the non-fault model is done by a comparison of results obtained from theoretical analysis and computer simulation of the model.

Real generator parameters of generators located at Kainji Hydo plant, Nigeria were used for the parallel unit connection to validate the non-fault model are stated below.

\section{Step-up Unit Parameter}

Generator rated voltage: $16 \mathrm{KV}$

Rated Power: $80 \mathrm{MW}$

Frequency: $50 \mathrm{~Hz}$

Stator winding capacitance: $0.6 \mu \mathrm{F}$

Grounding resistance: $16 / \sqrt{3}, 10 \mathrm{Amps}, 925 \Omega$

Circuit breaker capacitance: $0.1 \mu \mathrm{F}$

Step-up transformer Capacitance: $0.1 \mu \mathrm{F}$

Bus capacitance: $0.05 \mu \mathrm{F}$

Step-up transformer power: $184 \mathrm{MVA}$

Total third harmonic voltage produced in the generator calculated as $1 \%$ of rated voltage [5] is shown in table 1 for the load conditions under study.

Table 1: Total third harmonic voltage

\begin{tabular}{|l|l|l|l|}
\hline $\begin{array}{l}\text { Loading } \\
\text { Conditions }\end{array}$ & $E_{3}(V)$ & $\begin{array}{l}\% \text { phase neutral } \\
\text { Voltage(V) }\end{array}$ & $\begin{array}{l}\% E_{3} \\
\text { No-load } \\
\text { voltage(V) }\end{array}$ \\
\hline No-load & 160.0 & 1.73 & 100 \\
\hline Light load & 92.5 & 1.00 & 57 \\
\hline Full-load & 320.0 & 3.46 & 200 \\
\hline
\end{tabular}

The calculated and simulated voltage at the neutral and terminal of the generators for other loading conditions using the same formula above is shown in Table 2 .

Table 2: Parallel generator calculated, simulated voltage values and percentage error

Table 2A: Neutral Voltage

\begin{tabular}{|c|c|c|c|}
\hline $\begin{array}{l}\text { Loading } \\
\text { conditions }\end{array}$ & $\begin{array}{l}\text { Calculated } \\
\text { Voltages }(\mathrm{V}) \\
V_{n 1} \quad V_{n 2}\end{array}$ & $\begin{array}{l}\text { Simulated } \\
\text { Voltages }(\mathrm{V}) \\
V_{n 1} \quad V_{n 2}\end{array}$ & $\begin{array}{l}\text { Percentage } \\
\text { Error }(\%)\end{array}$ \\
\hline No-load & 114.7114 .7 & 115.8115 .8 & 0.95 \\
\hline Light-load & $\begin{array}{ll}66.3 & 66.3 \\
\end{array}$ & $\begin{array}{ll}66.8 & 66.8 \\
\end{array}$ & 0.75 \\
\hline Full-load & 229.5229 .5 & 231.6231 .6 & 0.92 \\
\hline
\end{tabular}

Table 2B: Terminal Voltage

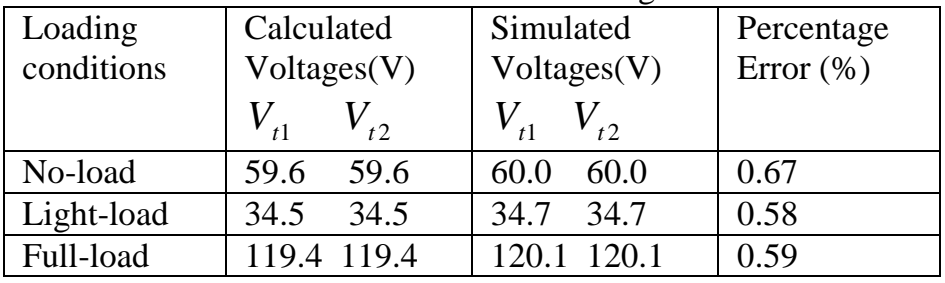

Where FL = full load, LL = light load, NL= no-load.

Comparing the results, the error of simulated from calculated values is less than $1 \%$ for all load conditions. This shows that the circuit model was built correctly using SIMULINK.

\section{CONCLUSIONS}

In this paper modelling parallel unit-connected generators have been presented and implemented using MATLAB/SIMULINK.

The circuit models can be used to study the influence of parallel unit-connected generators on third harmonic stator ground fault protection. When the parallel generator arrangement is operated in a single generator mode, the total capacitance at its terminal is modelled as a summation of its terminal capacitance and the capacitances at the terminal of the generator on standby up to the open circuit breaker.

When both generators are operated in parallel, the total capacitance at the terminal of each generator is modeled as the sum of the capacitances at the terminal of both generators. Comparison of the calculated and simulated values as presented in Table 2 with error of less than one percent show that the model can be relied on for study.

The range and character of third harmonic voltage feeding the protective relays for a parallel unit-connected generator of the second order can therefore be evaluated using the circuit models presented. 


\section{REFERENCES}

[1]. Pillai .P, Pierce .A, Bailey. B, Douglas.B, Mozina.C, Normand. C, Shipp. D, Stringer. T,Dalke.G, Jones.J, Fisher.J, Bowen.J, Padden.L. Lowell. J, Nichols .N, Young.R,(2003):“'Grounding and ground fault protection of multiple generator installations on medium-voltage Industrial and commercial power system", IEEE/IAS working group report, part 2.

[2]. Pillai .P, Pierce .A, Bailey. B, Douglas.B, Mozina.C, Normand. C, Shipp. D, Stringer. T,Dalke.G, Jones.J, Fisher.J, Bowen.J, Padden.L. Lowell. J, Nichols .N, Young.R, (2003): “Grounding and ground fault protection of multiple generator installations on medium-voltage Industrial and commercial power system", IEEE/IAS working group report, part 3.

[3]. Mozina.C (2009): "15 years experience with 100\% generator stator fault protection- what works, what doesn't and why" Industrial and commercial power systems technical conference - conference record IEEE.

[4]. Pope .J.W (April 1984): “A comparison of 100\% stator ground fault protection schemes for generator stator windings"Vol. PAS-103, pp 832-840.

[5]. Alcantara. R, Garcia. F, (2006): "100\% stator ground fault protection: a comparison of two protection methods, Department of industrial Electrical Engineering and automation, Lund Institute of technology.MSC Thesis, pp20-46.

[6]. Weijian.W, Xiaoping.X, Xiling. Z, (2003): New development of third harmonic ground fault protection schemes for turbine generator stator winding" Tsinghua University, Xuchang relay institute, pp. 250-253.

[7]. Ruiz-Mondragon, Mora-Florez, Perez-Londono, (2010): "Improvement of the thirdharmonic based stator ground fault protection for high resistance grounded synchronous generators", Rev. Fac. Ing. Univ.Antioquia, No 52, pp. 215-225.

[8]. Fulczyk .M, (2001): "Zero sequence voltages in unitconnected generator for different Methods of grounding generator neutral", developments in power system protection, conference publication No.47, IEEE.

[9]. Fulczyk .M, (2003): "Voltages third harmonic in generator stator winding at changes in generator load conditions" IEEE ABB corporate research.

\section{BIOGRAPHIES}

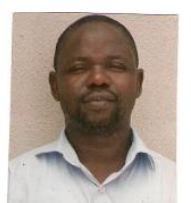

Gafari A. Adepoju was born in Nigeria and received the B.Tech. Hons Degree in Electronic and Electrical Engineering from the Ladoke Akintola University of Technology (LAUTECH), Ogbomoso, M.Sc. degree in Electrical and Electronics Engineering from University of Lagos and $\mathrm{Ph} . \mathrm{D}$ from LAUTECH, Ogbomoso, Nigeria. He is a Senior Lecturer in the Department of Electronic and Electrical Engineering, LAUTECH, Ogbomoso, Nigeria. His research areas of interest are power system Analysis and Electrical Machines and Application of FACTS controllers in Power Transmission systems

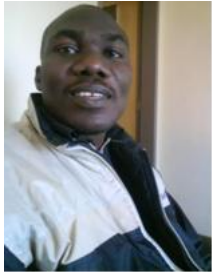

Ogunjuyigbe Ayodeji Samson received B.Eng. degree in 1991 from the Bendel state University, an M.Sc. with distinction in 1995 from the University of Lagos, Lagos, Nigeria, and a D.Tech. from the Tshwane University of Technology, Pretoria, South Africa. Since 1998, Ayodeji has lectured in the Electrical/Electronic Engineering department of the University of Ibadan, Nigeria. His research interests are in the field of performance improvement of Electric Machines, and contingency planning in power systems.

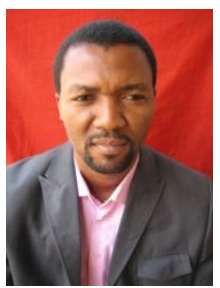

Brimmo T. Isaac was born in Nigeria and received the Technician Diploma and Advanced Technician Diploma in Electrical and Electronic Engineering Technology from City and Guilds of London Institute, Post-graduate Diploma in Electronic and Electrical Engineering from Ladoke Akintola University of Technology (LAUTECH) Ogbomosho and is presently a Master student in the Department of Electronic and Electrical Engineering, LAUTECH, Ogbomoso, Nigeria. He is an Assistant Manager in the Electrical Department of Mainstream Energy Solutions Limited - Kainji Hydro Power Plant, Nigeria. His research interest is in the area of Power System Protection with particular interest in Generator Protection. 